\title{
Post-procedural Drainage versus no Drainage in Laparoscopic Cholecystectomy at DHQ Hospital Charsadda, Pakistan
}

\author{
Muhammad Bilal ${ }^{1}$, Viqar Aslam², Zaheer ud din ${ }^{3}$, Waqas Jan ${ }^{4}$, Inamullah', Shehzad Khan ${ }^{3}$, Ali Hasnain \\ Malik ${ }^{3}$ \\ ${ }^{1}$ District Surgeon, District Headquarter Hospital, Charsadda, Khyber Pakhtunkhwa-Pakistan \\ ${ }^{2}$ Associate Professor, Department of Surgery, Lady Reading Hospital, Peshawar Khyber Pakhtunkhwa-Pakistan \\ ${ }^{3}$ Medical Officer, District Headquarter Hospital, Charsadda, Khyber Pakhtunkhwa-Pakistan \\ ${ }^{4}$ General Surgeon, District Headquarter Hospital, Charsadda, Khyber Pakhtunkhwa-Pakistan \\ ${ }^{5}$ Senior Medical Officer, District Headquarter Hospital, Charsadda, Khyber Pakhtunkhwa-Pakistan
}

\begin{abstract}
Background: Laparoscopic cholecystectomy (LC) is the treatment of choice for symptomatic gall stones but controversy regarding the routine use of drainage after elective LC still exists. The objective of this study was to determine the efficacy of post-procedural drainage versus no drainage after simple laparoscopic cholecystectomy. The postoperative complications were also evaluated in both groups after the LC procedure.

Material and Methods: This Randomized controlled trial (RCT) was conducted in patients who underwent Laparoscopic cholecystectomy according to a pre-set inclusion criterion. Ninety-three patients were randomly assigned into group A (with drainage tube) and group B (without drainage tube) using sealed opaque envelopes containing computergenerated random numbers. Primary (like duration of hospital stay, Postoperative pain) and secondary outcomes (like postoperative complications) were noted in both groups. Chi-square, Fischer exact test and Mann witney $U$ test were applied as appropriate and statistical significance was established at $P<.05$.

Results: The number of patients with hospital stay exceeding two days were more in group A ( $n=23 ; 51.1 \%$ ) than $B$ $(n=13 ; 28.8 \%)(P<.05)$. Group A presented with more postoperative complications but differences between the two groups were statistically non-significant. Both Groups experienced a high level of pain at six hours of surgery followed by progressive decrease in severity at 24 and 48 hours, respectively $(P=.06)$.

Conclusions: Post-procedural drain placement after laparoscopic cholecystectomy has no advantages as there is no significant difference in post-operative complications and duration of hospital stay in drainage versus no drainage groups.

Key words: Complications, Laparoscopic cholecystectomy, Pain severity, Postoperative Drain.
\end{abstract}

\begin{tabular}{|c|c|c|}
\hline Authors' Contribution: & Correspondence: & Article info: \\
\hline $\begin{array}{l}{ }^{1} \text { Conception; Literature research; } \\
\text { manuscript design and drafting; }{ }^{2-5} \text { Critical } \\
\text { analysis and manuscript review; Data } \\
\text { analysis; Manuscript Editing. }\end{array}$ & $\begin{array}{l}\text { Muhammad Bilal } \\
\text { Email: bilalsurg@gmail.com }\end{array}$ & $\begin{array}{l}\text { Received: May 15, } 2020 \\
\text { Accepted: June 22, } 2021\end{array}$ \\
\hline
\end{tabular}

Pakistan. J Islamabad Med Dental Coll. 2021; 10(2): 105-109. Doi: 10.35787/jimdc.v10i2.554 


\section{Introduction}

Stones in the duct of the gallbladder, that result in blockage is amongst the most common illness related to the gastrointestinal tract. Laparoscopic cholecystectomy (LC) is used in the treatment of over $80 \%$ of cholelithiasis cases across the world. LC provides a safe and effective treatment for most patients with symptomatic gallstones and has become the treatment of choice. This procedure proves to be less invasive management of gallstones than open cholecystectomy, thus leading to faster recovery and few postoperative complications. ${ }^{1-5}$

To prevent bile or blood collection that might become infected, post-operative drains have been routinely placed by many surgeons to avoid any further interventional procedures. Another reason for drainage is to allow carbon dioxide used for insufflation during laparoscopy, leave via drain site leading to decreased shoulder pain and postoperative nausea and vomiting. ${ }^{3-6}$ However, some surgeons believe that the use of drains only increases the wound infection rate by $2 \% .{ }^{3}$ In a randomized controlled trial, Tzovaras and colleagues also assessed the usefulness of drains in elective LC, so this issue is still generating a significant debate. ${ }^{7}$

This clinical study was designed to find out whether the placement of post-operative drain was valuable or not with regards to post-operative outcomes and complications. So, the efficacy of placement of drains versus no drain placement in LC was assessed. The complications were evaluated in both groups after the LC procedure.

\section{Material and Methods}

This RCT was conducted in the surgical unit of District Headquarter Hospital (DHQ), Charsadda, Khyber Pakhtunkhwa, Pakistan from February till December 2018. Approval for the study was obtained from the Ethics Committee of the hospital. A sample size of 90 patients was calculated using the WHO calculator. ${ }^{7}$ After fulfilling the eligibility criteria and dropouts, 90 patients were recruited for this study (Figure 1). Patients with symptomatic gall stones confirmed on ultrasonography, hematological and biochemical tests were included in the study while patients with cholangitis and pancreatitis were excluded. They were randomly assigned into two groups ( $A$ \& B), ( $n=45$ for each group) using sealed opaque envelopes containing computer-generated random numbers.

In group A, a drain made of polyethylene was placed in each patient at the end of the LC through the trocar $(5 \mathrm{~mm})$ at the anterior axillary line for 48 hours. ${ }^{12}$ Group B patients were without postprocedural drains. The study was conducted after proper evaluation of patients undergoing LC procedures. Standard surgical protocols were followed for the procedure. All patients received one dose of Ceftriaxone (1 $\mathrm{gm}$ ) during the induction of general anesthesia (GA). Protocols regarding preand post-operative placement of drains and induction of analgesia were the same for both groups. Patients were operated by the same surgeon and his team using similar protocols. Primary outcomes including duration of hospital stay, post-operative pain, and secondary outcome like post-operative complications were noted in both groups.

Data was collected on a structured proforma. Pain as a significant finding was evaluated by using Numerical Rating Scale (NRS) in which a numbering from 0 to 10 was given to the patient on a ruler. Patients chose their level of pain according to the numbers. Number ' 0 ' on the scale represented 'No pain at all' while ' 10 ' on the scale indicated 'unbearable pain'. 


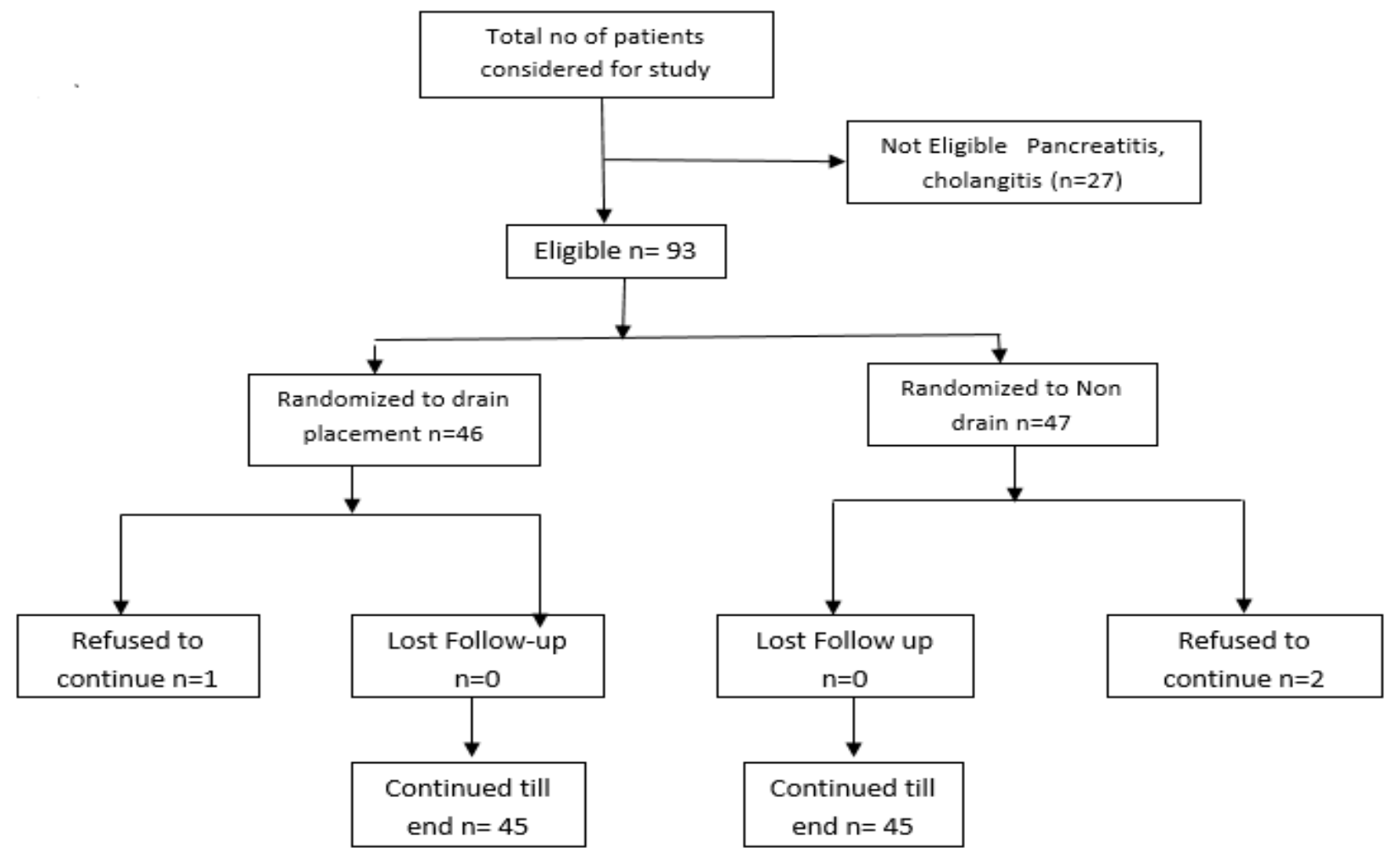

Figure 1: Flow Chart depicting randomization in the trial protocol.

The recordings were taken after 06,24 , and 48 hours of surgery. Both groups received $75 \mathrm{mg}$ of diclofenac sodium intramuscularly every eight hours, postoperatively and from the next day oral combination of ibuprofen and paracetamol was started.

Data were analyzed through Statistical Package for Social Science (SPSS) version 23. Frequencies (percentage) and median (range) were calculated. Chi-square, Fischer exact test and Mann witney $U$ test were applied as appropriate and statistical significance was established at $P<.05$.

\section{Results}

In Group A there were 10 males and 35 females while in Group B, 9 males and 36 females were included. The mean age of patients in group $A$ was $38.5 \pm 5.28$ years and for group $B$ it was $39.12 \pm 5.07$ years. The number of patients with hospital stay exceeding two days were more in group $A(n=23$; $51.1 \%)$ than $B(n=13 ; 28.8 \%)(P<.05)$. Group $A$ presented with more postoperative complications but differences were statistically non-significant (Table I). No hernia, reoperation, or death was reported in both groups.

\begin{tabular}{|l|c|c|c|}
\hline \multicolumn{4}{|c|}{ Table I: List of postoperative complications in both } \\
groups \\
\hline Complications & $\begin{array}{c}\text { Group A } \\
\text { (With } \\
\text { Drain) }\end{array}$ & $\begin{array}{c}\text { Group B } \\
\text { (Without } \\
\text { Drain) }\end{array}$ & $\begin{array}{c}{ }^{*} \boldsymbol{P} \text { - } \\
\text { value }\end{array}$ \\
\hline $\begin{array}{l}\text { Pain in right } \\
\text { shoulder }\end{array}$ & $6(13.3 \%)$ & $5(11.1 \%)$ & 0.17 \\
\hline $\begin{array}{l}\text { Infection } \\
\text { (Surgical site) }\end{array}$ & $3(6.6 \%)$ & $1(2.2 \%)$ & 0.18 \\
\hline $\begin{array}{l}\text { Infection } \\
\text { (Respiratory) }\end{array}$ & $1(2.2 \%)$ & 0 & 0.71 \\
\hline Nausea & $22(48.8 \%)$ & $11(24.4 \%)$ & 0.32 \\
\hline Vomiting & $15(33.3 \%)$ & $9(20 \%)$ & 0.19 \\
\hline
\end{tabular}

${ }^{*} P$-value $<.05$ was taken as statistically significant 
Both Groups experienced a high level of pain at six hours of surgery followed by progressive decrease in severity at 24 and 48 hours, respectively (Table II). There was no significant difference in pain analyzed in both groups $(P=.06)$.

\begin{tabular}{|c|c|c|}
\hline \multicolumn{3}{|c|}{$\begin{array}{c}\text { Table II: Postoperative Pain Score (Median and } \\
\text { Range) }\end{array}$} \\
\hline $\begin{array}{l}\text { Postoperative } \\
\text { Hours }\end{array}$ & $\begin{array}{l}\text { Group A (with } \\
\text { Drain) }\end{array}$ & $\begin{array}{l}\text { Group B (without } \\
\text { Drain) }\end{array}$ \\
\hline 6 & $6(0-9)$ & $5(0-9)$ \\
\hline 24 & $4(0-9)$ & $3(0-7)$ \\
\hline 48 & $2(0-7)$ & $2(0-7)$ \\
\hline
\end{tabular}

${ }^{*} P$-value was $>.05$

\section{Discussion}

Laparoscopic surgery has many advantages as it is more reliable, precise and cause less damage as compared to conventional surgery. The routine placement of drain has become a part of the operation, because of fear of collection of blood or bile for a long period or to allow the escape of carbon dioxide accumulated during the procedure. However, controversies have surrounded this practice. $^{8,9}$

Mean hospital stay of patients in the group without drainage was less in our study, which is similar to the studies conducted by Gurusamy et al. ${ }^{10}$ and Satinsky et al. ${ }^{11}$ Patients complain of postoperative shoulder pain, nausea and vomiting, due to use of a shortterm drain postoperatively based on the theory that high-pressure $\mathrm{CO} 2$ insufflation during the operation and the accumulation of gas in the right subphrenic area leads to these complaints. ${ }^{3-6}$

The results showed no significant differences in postoperative complications in the two groups (with and without drain) i.e., wound infections, mortality, respiratory infection and/or nausea. This is in accordance with the observations of Gurusamy et al. and Valappil et al. ${ }^{8,10}$ However many studies have revealed that the use of drain is associated with increased morbidity., ${ }^{8,12-15}$ According to literature, drainage prevent complications as it allows $\mathrm{CO} 2$ used for insufflation during laparoscopy procedure leave via the drain site, while according to others drain is a source of infection. ${ }^{16-20}$

NRS score in this study revealed that every patient experienced different level of pain, though there was no significant difference in pain scores in both groups. Group A experienced a high level of pain at 24-48 hours of surgery. Uchiyama et al. ${ }^{15}$ and Tzovaraset et al. ${ }^{7}$ also suggested that drain placement was linked with increased pain. ${ }^{8}$

The results of this study showed that laparoscopic cholecystectomy without drainage has more advantages over LC with drainage, as well as reduced hospital stay. These results are in accordance with the studies done by Sharma and Lucarelli. ${ }^{12,13}$ Therefore, it proves that laparoscopic cholecystectomy without drainage is safest and should be considered as the option of choice for uncomplicated cholecystitis. If a drain is used, it should be removed within 24 to 48 hours, as recommended by other authors. ${ }^{12,14}$

The major limitation of this clinical trial was that it was a single center study on a limited number of patients. A multi-center clinical trial enrolling large number of patients should be carried out to authenticate findings of our study.

\section{Conclusion}

We conclude that post-procedural drain placement after laparoscopic cholecystectomy has no advantages as there is no significant difference in post-operative complications and duration of hospital stay in drainage versus no drainage groups. 


\section{References}

1. Strasberg SM. Tokyo Guidelines for the Diagnosis of Acute Cholecystitis. J Am Coll Surg. 2018; 227(6): 624. Doi: 10.1016/j.jamcollsurg.2018.09.005.

2. Kapoor T, Wrenn SM, Callas PW, Abu-Jaish W. Cost analysis and supply utilization of laparoscopic cholecystectomy. Minim Invasive Surg. 2018; 7838103. Doi: 10.1155/2018/7838103.

3. Feng JW, Yang XH, Liu CW, Wu BQ, Sun DL, Chen XM, et al. Comparison of Laparoscopic and Open Approach in Treating Gallbladder. Cancer J Surg Res. 2019; 234: 269-76. Doi: 10.1155/2018/7838103.

4. Jeans PL. Murphy's sign. Med J Aust. 2017; 206(3): 115-16. Doi: 10.5694/mja16.00768.

5. Kose SH, Grice K, Orsi WD, Ballal M, Coolen MJL. Metagenomics of pigmented and cholesterol gallstones: the putative role of bacteria. Sci Rep. 2018; 8(1): 11218. Doi: 10.1038/s41598-018-295718.

6. Sarawagi R, Sundar S, Raghuvanshi S, Gupta SK, Jayaraman G. Common and uncommon anatomical variants of intrahepatic bile ducts in Magnetic Resonance Cholangiopancreatography and its clinical implication. Pol J Radiol. 2016; 81: 250-5. Doi: 10.12659/PJR.895827.

7. Tzovaras G, Liakou P, Fafoulakis F, Hatzitheofilou C. Is there a role for drain use in elective laparoscopic cholecystectomy? A controlled randomized trial. Am J Surg. 2009; 197: 759-63. Doi: 10.1016/j.amjsurg. 2008.05.011.

8. Valappil MV, Gulati S, Chhabra M, Mandal A, De Bakshi S, Bhattacharyya A, et al. Drain in laparoscopic cholecystectomy in acute calculous cholecystitis: a randomized controlled study. Postgrad Med J. 2020; 96: 606-9. Doi: 10.1136/postgradmedj-2019-136828.

9. Gurer A, Dumlu EG, Dikili E, Kiyak G, Ozlem N. Is a drain required after laparoscopic cholecystectomy? Eurasian J Med. 2013; 45(3): 181-4. Doi: 10.5152/eajm.2013.37.

10. Gurusamy KS, Samraj K, Mullerat P, Davidson BR. Routine abdominal drainage for uncomplicated open cholecystectomy. Cochrane Database Syst Rev. 2007; 4: CD006004. Doi: 10.1002/14651858.CD006003.

11. Satinsky I, Mittak M, Foltys A. Subhepatic drainage in laparoscopic cholecystectomy-a necessity or an overused tradition? Rozhl Chir. 2003; 82: 427-31. PMID: 14619087.

12. Sharma A, Gupta SN. Drainage versus no drainage after elective laparoscopic cholecystectomy. Kathmandu Univ Med J. 2016; 14(53): 69-72. PMID: 27892445.

13. Lucarelli P, Picchio M, Martellucci J, De Angelis F, Di Filippo A, Stipa F, Spaziani E. Drain after laparoscopic cholecystectomy for acute calculous cholecystitis. A pilot randomized study. Indian J of Surg. 2015; 77(2): 288-92. Doi: 10.1007/s12262-012-0797-9.

14. Mandrioli M, Inaba K, Piccinini A, Biscardi A, Sartelli $M$, Agresta $F$, et al. Advances in laparoscopy for acute care surgery and trauma. World J Gastroenterol. 2016; 22(2): 668. Doi: 10.3748/wjg.v22.i2.668.

15. Uchiyama K, Tani M, Kawai M, Terasawa H, Hama $T$, Yamaue $\mathrm{H}$. Clinical significance of drainage tube insertion in laparoscopic cholecystectomy: a prospective randomized controlled trial. J Hepatobiliary Pancreatic Surg. 2007; 14(6): 551-6. Doi: 10.1007/s00534-007-1221-x.

16. CM T. Sabiston textbook of surgery. Noida. Elsevier (18 ed). 2009; 2: 1556.

17. Hawasli A, Brown E. The effect of drains in laparoscopic cholecystectomy. J Laparoendosc Surg. 1994; 4(6): 393-8. Doi: 10.1089/lps.1994.4.393.

18. Hawasli A. To drain or not to drain in laparoscopic cholecystectomy: rationale and technique. Surg Laparosc Endosc. 1992; 2(2): 128-30. PMID: 1341518.

19. Jorgensen JO, Gillies RB, Hunt DR, Caplehorn JR, Lumley T. A simple and effective way to reduce postoperative pain after laparoscopic cholecystectomy. Aust NZ J Surg. 1995; 65(7): 466-9. Doi. 10.1111/j.1445-2197.1995.tb01787.x.

20. Abbott J, Hawe J, Srivastava P, Hunter D, Garry R. Intraperitoneal gas drain to reduce pain after laparoscopy: randomized masked trial. Obstet Gynecol. 2001; 98(1): 97-100. Doi: 10.1016/S00297844(01)01383-7. 